\title{
Towards an Autonomous and Smart Water Tank System
}

\author{
Ali Sayyed ${ }^{1}$, Muhammad Waqar Aziz ${ }^{2}$ \\ Department of Computer Science, CECOS University of IT \& Emerging Sciences, \\ Peshawar, 25000, Pakistan, \\ ${ }^{1}$ alisayyed@cecos.edu.pk, ${ }^{2}$ waqar@ cecos.edu.pk
}

\begin{abstract}
Water is a mandatory need for all human beings. Without water, life is not possible. The increasing population of the world has an inverse relationship with the availability of clean water. It is used for different purposes e.g., drinking, washing, cooking, agriculture, industries, etc. It is one of the precious natural resources. Unfortunately, excessive use and wastage lead to serious circumstances for other consumers. The major causes of the wastage are overflow in overhead tanks, damaged pipelines, open and faulty water taps and valves, and unnecessary consumption. Dry running of the water pumps is another important issue concerning water pumps. When the water from the main pipeline is not reaching them or the flow rate of water is too low, the water pump will consume more electric supply, which shorten their working span. On the other hand, inappropriate voltage is also damaging the water pump motor. The drinking water with an average quality of purity is responsible for a healthy nation. The water with inadequate levels of $\mathrm{pH}$ and turbidity can invite water-borne diseases. After considering all the problems, a need for proper solutions is highly recommended. In this regard, we found an adequate solution in the form of an autonomous system called Smart Water Tank. Our intention is not limited to overcome the wastage of the water only but also to control the unnecessary use of resources-electricity and water pump, the monitoring of drinkable water quality concerning $\mathrm{pH}$ and turbidity level. This flexible, portable, and economical automated system will be responsible for automatically switching ON/OFF the water pump motor, monitoring the water flow rate, electricity magnitude, and its temperature-needed for the water pump motor, during and before it takes starts for filling. All the updates for the different parameters will be displayed by the LCD and LEDs installed on the system-locally as well as on the smartphone app connected with Smart Water Tank System via server.
\end{abstract}

Key words : Autonomous Systems, Smart Water Tank,

\section{INTRODUCTION}

Water is a valuable resource for a sustainable life. As the world's population is increasing, the availability of clean water is becoming a major problem. Conservation and distribution of water, nowadays, can also help in this regard. Water tanks are structures used to conserve water and its use later. The need of a water tank is as old as of civilized man, providing storage of water for different purposes such as drinking, food preparation, irrigation, etc. The most fundamental classification of reinforced water tanks is based on whether they are on the ground or beneath [1]. Overhead water tanks, also known as elevated water tanks, are located on the terrace of the building to supply water to the entire house. This overhead tank is either filled through the main water supply or from an underground water source. Water flows under gravity from it as the water tank is at height of the building [2]. To fill an overhead tank the first step is to install a pump machine. A water pump is a device used to transport liquid from one place to another [3]. Water pumps are powered by diesel fuel, electricity, wind, solar energy, etc. [4]. Centrifugal pumps are considered as best pump choice for lower viscosity and high flow rates. Once the pump machine is powered, water from the main source or underground storage tank is sent to the overhead tank [5].

Water safety and quality are essential to human development and wellbeing. The key test for water quality is the measurement of its turbidity [6]. Turbidity is the cloudiness or haziness of a fluid due to the presence of a large number of individual particles that are generally not visible to the naked eye, just like smoke in the air. Turbidity levels are much higher in water from surface water sources (e.g., streams, rivers, and lakes) than from groundwater sources. Turbidity is measured and reported in Nephelometric Turbidity Units (NTU). It is an optical measurement of water's ability to scatter and absorb light rather than transmit it in straight lines. Turbidity levels can range from less than 1 NTU to more than 1000 NTU. At 5 NTU water is visibly cloudy, whereas at $25 \mathrm{NTU}$ it is murky [7]. According to the WHO, the maximum allowed turbidity in drinking water should not be more than 5 NTU and should ideally be below 1 NTU [8]. Another important factor of water quality is its $\mathrm{pH}$ (potential of Hydrogen). The $\mathrm{pH}$ is one of the most common water quality tests performed [9]. A pH level is the measurement of acid-base equilibrium, and that number indicates whether a substance is acidic or basic. The U.S, Environmental 
Protection Agency (EPA) recommends that municipal drinking water suppliers should keep their water supply at a $\mathrm{pH}$ of 6.5 to 8.5 , which is considered a safe range for drinking [10].

A lot of water gets wasted because of improper distribution and monitoring systems. These imbalanced systems are responsible for providing clean water to one area but at the same time deprived other. If the quantity of water is consumed according to the needs then no doubt it also contributes towards the preservation of these natural resources. Some common reasons in our daily life for the wastage of water are overflow in the pipelines with high pressure, overflow of the water tank, excessive usage of water than needed and so on. In a traditional water tank system, one has to switch ON the pump motor manually on encountering the water tank empty, and later on turn it OFF, when the water starts flowing through the overflow pipe. During this filling session, human full-time engagement is required, which can be overburdened in case of high consumption of water. Also, the pump failure occurs most frequently in these systems. The possible reasons are dry running or high temperature of pumps during filling. The replacement of pumps is costly and needs a lot of effort (in terms of installation/un-installation and carrying). The other inconsistencies in the manual system can be low voltage, dry running (or a pump is not running at all), low water level, and inappropriate quality of drinking water, etc.

To overcome the above-mentioned problems, an automated system named Smart Water Tank is presented in this paper. The proposed system is based on the Internet of Things (IoT), which consists of smart machines, objects, environments and infrastructures [11]. IoT involves the utilization of the sensor devices to sense and collect data from remote sites, and then share the same data via the internet where it can be used according to the interests. The developed system involves different sensors, responsible for filling the water tank automatically when the level of water becomes low. Other functionalities provided by the developed system are: continuous monitoring of the water flow rate to the water pump, finding the temperature of the water pump, availability of the electric supply and its magnitude either switched ON pump is running or not, availability of the water in the tank, and finding $\mathrm{pH}$ and turbidity of water in the tank. The user can see all this information on a smartphone application connected to the Blynk cloud via the internet connectivity and also via LEDs (light-emitting diode) and LCD (liquid crystal display) attached to the Smart Water Tank. Blynk is an IoT platform which allows to easily and remotely control the hardware. Additionally, the data generated by sensors can be viewed, stored, and visualized etc. over the internet.

One can utilize the developed system in different ways, for instance, using at personal level for residencies and buildings for filling overhead tanks; and at industrial level especially when there are many tanks with fluids. Monitoring the status of many tanks and their pumping motors at the same time is inconvenient for humans, which can be achieved by the developed system. Similarly, the big field water tanks used in farming and agriculture can be filled very efficiently using the proposed Smart Tank. As in the traditional filling system one has to switch ON/OFF the pumps and wait for the time when the big tank gets filled. The developed system can also be used in the hospitals and special care centers where the quality of the drinking water matters a lot for the patient and residents. The industries responsible for sale of distilled water can also get benefits, as they can fill their tanks and check the quality of water with the developed system. Overall, the developed system would pull out the user from the extra efforts and financial burdens.

\section{LITERATURE REVIEW}

The authors in [12] developed an embedded control system for an automatic water pump to fill the overhead water storage tank. The system is based on the utilization of microcontroller (AT89C52) to automate the process of filling. This intelligent system detects the water level in the tank and switches on/off the pump accordingly along with displaying the status on the LCD screen. Another automated system is designed for switching on/off (subject to the water level) the domestic water pump along with the LED indicator [13]. The developers used electronic discrete components (555 timer IC, transistor, resistors, relay etc.) to develop the circuitry. This mechanism is responsible for filling the overhead water storage tank automatically along with the display of the status through different LEDs.

A wireless automatic system is implemented for sending the water from sump (underground water storage tank) to the overhead water storage tank [14]. It uses two Radio Frequency transceivers along with a microcontroller each installed at the tank and sump. These two transceivers are used for wireless communication with the help of microcontroller. When the sensor of overhead tank detects water at low level, it communicates with the sump transceiver to switch ON the water pump and turns it OFF when the water is filled up to the required level. In addition, if the sump is empty then buzzer will ring to tell that sump is empty. Similarly, a smart water tank management system is designed using Atmega 128A microcontroller [15]. In the water tank, contact sensors are deployed for water level sensing, whereas an LCD screen is used to display the current status of the water level.

In [16], two wireless radio transmitters are connected, one with water level detector and second with the digital switch responsible for switching ON/OFF the water pump. Both of the wireless radio transmitters are also integrated with a $\mathrm{WiFi}$ 
router. The transmitter with water tank fetches and transmits the water level information, which is accessed via a smart phone. If the smart phone is not in the communication range of the WIFI router then the communication between the application and the water pump is accomplished by the Internet. The controller application installed on the android smart phone is responsible for switching ON/OFF the water pump. The authors in [17] designed a smart water management system that consists of two sensors connected to the Raspberry Pi chipset. In this system, one sensor is an ultrasonic sensor, used to find the water level, whereas the other is $\mathrm{pH}$ sensor, used for measuring the quality of water. The statuses of both sensors are stored in the local database as well as sent to the cloud environment for future data analytics.

In [18], the authors used an ultrasonic sensor to measure the water level and display it on the LCD. On encountering the low water level, the water pump gets started automatically and it stops when the tank gets full. To achieve this operation, Arduino UNO R3 is used along with ASK RF transmitter for switching ON/OFF the water pump. In contrast, IoT platform is used with Arduino UNO in [19]. The three different levels of water (i.e., maximum, nominal and minimum) are judged by ultrasonic sensors. On the lowest level of water, the motor starts automatically and stops when it reaches to the maximum level set by the user. However, user can manually starts/stops motor if the water level is between minimum and maximum via android application installed. The system is accessed by smart phone but internet connectivity is mandatory. The GUI application also tells the motor status i.e., ON/OFF along with the level of water in percentage.

Shah et al. [20] used ESP8266 Wifi module, as microcontroller, that receives data about the water level from the ultrasonic sensor and sends it to the cloud called firebase. It also retrieves the data (e.g., minimum, maximum values of the water level etc.) from the same cloud which are set by the user from an application installed on android smartphone. Similarly, IoT platform is used along with the Arduino UNO and a few sensors. An overhead water level is sensed by the ultrasonic sensor. If the level is less than maximum then the water pump motor starts itself and stops when the level reaches to the maximum. But before switching on the water pump, this system ensures the availability of electric power-to drive water pump, and continuous flow of water in the main water pipe. On the inaccessibility of electric power, the user is informed through SMS for taking further necessary actions.

\section{METHODOLOGY}

This work followed the iterative software development life cycle approach. It means that the system was designed and developed in several cycles (iterations), where new features were added in each iteration. The proposed system was developed using the Arduino UNO microcontroller board and Node MCU firmware and development kit. The programming code was written in Arduino IDE, which was then compiled and uploaded to the Arduino board. To this end, some ready-made libraries were searched and installed to provide the required behavior and functionality of each module. For example, the built-in Liquid Crystal library makes it easy to talk to character LCD displays. Some LEDs were also mounted on the tank for displaying different levels of water in the tank, temperature of the pump, internet connectivity and motor status.

Some sensors such as $\mathrm{pH}$ sensor, Turbidity Sensor, Ultrasonic Sensor etc., needed proper calibration before their use. To this end, some mathematical calculations were performed based on plotting graphs between different voltage values and known values obtained from sensors. The graphical user interface was developed using the built-in widgets provided by the Blynk application. These widgets were then linked with virtual pins, e.g., in Figure 1 Virtual Pin V2 is linked with "Value Display" widget labeled "pH of Water" that is going to be updated every second. Similarly, other virtual pins were connected with the concerned Value Display widgets to display the sensors data. Moreover, the necessary Blynk libraries were set up to transfer the data from Smart Water Tank System to Blynk Cloud and redirect it to the Smart Phone application. This was achieved using the Authentication Token (send by the Blynk server), WIFI SSID (Service Set Identifier) and Passwords while programming the Node MCU. Although several Protocols (such as Ethernet, Bluetooth, WIFI, GSM/3G/LTE, USB etc.) can be used to connect the Arduino with Blynk [21], WiFi connectivity is used in this work.

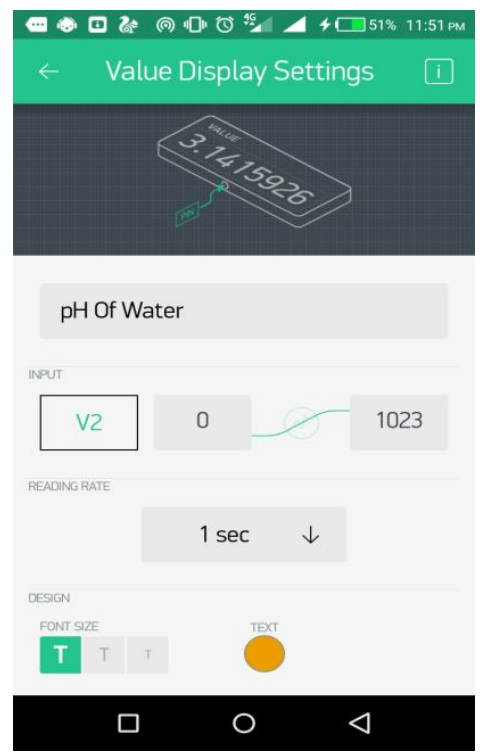

Figure 1: Linking Widgets with virtual Pins 


\section{THE PROPOSED SYSTEM}

\subsection{Hardware Components}

The hardware components used to develop the proposed system comprised of the following sensors.

1. $\mathrm{pH}$ sensor

The $\mathrm{pH}$ sensor measures the level of acidity or alkalinity of any fluid. The $\mathrm{pH}$ scale ranges from $0-14$, with levels less than 7 considered acidic, levels greater than 7 considered alkaline, and a $\mathrm{pH}$ of 7 considered neutral [22].

2. Turbidity Sensor

Turbidity sensor measures the haziness or cloudiness of a fluid. Turbidity is caused by the increased number of tiny particles which cannot be seen by the naked eyes. The turbidity sensor contains a light transmitter and a receiver, which receives most of the light in clear waters. As turbidity of the water increases, the light receiver receives less and less light. The sensor triggers when the light received is below a certain threshold.

\section{Ultrasonic Sensor}

Ultrasonic sensors are great tool to measure distance without actual contact. The ultrasonic sensor is used in this work to tell the level of available water in the tank. It monitors the water level all the time by the calculating the distance between the water level and sensor itself.

\section{AC Voltage Sensor}

The AC Voltage Sensor is responsible for reading the direct AC Voltage from the main power supply. This module is capable for reading voltages from $0-250 \mathrm{~V}$ in both 50 and 60 $\mathrm{Hz}$ in a single phase. However, the voltage of the main supply is converted to Arduino voltage level before reading.

\section{Water Flow Sensor}

The Water Flow Sensor is used for flow rate \& volume measurements. We measured the number of pulses using Arduino and then calculated the flow rate in liters per hour (L/min) using the conversion formula [55].

6. Vibration Sensor

The working principle of the vibration sensor is very simple. Whenever this module feels any vibration, it gives out high signal otherwise output signal remains low. The magnitude of the vibration is set by the onboard potentiometer. This potentiometer sets a threshold value. If the vibration of the module goes beyond the threshold then output signals go high.

\section{Temperature Sensor}

This is a pre-wired and waterproofed (with heat shrink) version of the DS18B20 sensor. It is handy when measuring something far away, or in wet conditions. While the sensor is good up to $125^{\circ} \mathrm{C}$, the cable is jacketed in PVC so keeping it under $100^{\circ} \mathrm{C}$ is suggested. The 1 -wire digital temperature sensors are fairly precise $\left( \pm 0.5^{\circ} \mathrm{C}\right.$ over much of the range) and can give up to 12 bits of precision from the onboard digital-to-analog converter.

\subsection{Data communication}

On getting start, the data from the different sensors attached with the Arduino UNO is sent to the Node MCU through serial communication. The Node MCU then establishes a connectivity with the Blynk Server via internet. On successful connection, a message is displayed on the LCD attached to the smart tank. In addition, a LED will start and remain blinking till the system is connected with the Blynk server. Once the Blynk server receives the data, it sends it to the user's smart phone app. The complete process is depicted in Figure 2.

\subsection{Working}

As the water level reaches the pre-defined minimum level, the water pump starts automatically. The developed system uses a submersible water pump which runs at $220 \mathrm{AC}$ voltage. While the water is being filled in the water tank, the ultrasonic sensor continuously monitors the water level. When the water reaches the maximum level the water pump stops automatically.

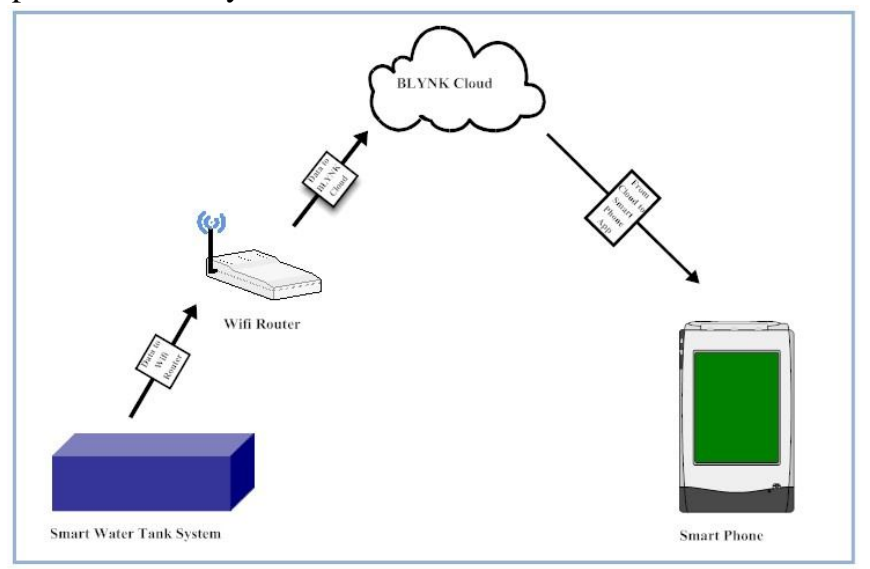

Figure 2: Working of the Proposed System

\section{CONCLUSION}

Water safety and quality are the essential to human development and wellbeing. Usage of safe water is playing vital role in promoting health. The $\mathrm{pH}$ and turbidity levels are important factors in the contribution of healthy lives of humans. In this work a Smart Water Tank System is developed keeping the safety measures and conserving resources under consideration. The developed system is capable of monitoring the water level, temperature of the water pump before and during running, water flow rate, status of water pump (either running or not), $\mathrm{pH}$ level and turbidity levels. Furthermore, it switches the water pump ON/OFF based on the level of the water tank. This eliminates the need of person to engage with the water pump and controls the wastage of water and other concerned resources. The user can monitor the status of all activities on an LCD and on the Smart Phone application. The entire system is easy to setup, as little knowledge of the electronics is required. In addition, 
no complicated configuration is required after initial setup. Also, the components used in the developed system are easily available and replaceable. This system was tested under different conditions and for different durations and was found to be working correctly. The testing and close observations of both the individual components and the entire system were found successful.

\section{REFERENCES}

1. W. O. Ajagbe, E. O. Ilugbo, J. O. Labiran, and A. A. Ganiyu, Analysis and Design of a Fully Submerged Underground Water Tank Using the Principle of Beam on Elastic Foundation, in UITECH Conference, pp. 1-10, 2015.

2. Nidi Patel, Water Storage Tanks (for a Residential Water Storage), Gharpedia, viewed 28 May 2019, $<$ https://gharpedia.com/water-storage-tanks/> 2019.

3. A. Emiliawati. A study of water pump efficiency for household water demand at Lubuklinggau, in AIP Conference Proceedings (Vol. 1903, No. 1,). AIP Publishing. 2017, pp. 100003.

4. Essays UK, Power the Water Pump For Irrigation System Engineering Essay, Essays UK, viewed 27 May 2019 ,

$<$ https://www.ukessays.com/essays/engineering/power-t he-water-pump-for-irrigation-system-engineering-essay. php>, 2018.

5. Penguine Tank, How water is filled in overhead tanks, Quora, viewed 23 May 2019, $<$ https://www.quora.com/How-is-water-filled-in-overhe ad-tanks>, 2017.

6. Wikipedia, Turbidity, Wikipedia, viewed 28 May 2019, <https://en.wikipedia.org/wiki/Turbidity>, 2019.

7. South-East Kelowna Irrigation District, Turbidity and Health Risks, South East Kelowna Irrigation District, viewed 29 May 2019, < https://www.sekid.ca/water-quality/turbidity/>, 2019.

8. Lenntech, Water Treatment Solution, Lenntech, viewed 10 May 2019, <https://www.lenntech.com/turbidity.htm\#Which is the maximum allowed turbidity in drinking water?>, 2019.

9. PG Mr. Brain Oram n.d., pH in the Environment Ecosystem, Water Research Center, viewed 25 May 2019,

<https://www.water-research.net/index.php/ph-in-the-e nvironment $>$

10. Healthline, $\mathbf{p H}$ of Drinking Water: Acceptable Levels and more, Healthline, viewed 20 May 2019, <https://www.healthline.com/health/ph-of-drinking-wat er\#unsafe-ph-for-water>, 2019.

11. Sharma, V. and Tiwari, R. A review paper on "IOT" \& It's Smart Applications, International Journal of Science, Engineering and Technology Research (IJSETR), Vol. 5, issue 2, pp. 472-476, 2016.
12. Ebere, E.V., Oladipo Onaolapo Francisca. Microcontroller based Automatic Water level Control System, PhD thesis, 2013.

13. Raghavendra. R, M. Uttara Kumari and S. A. Hariprasad, Implementation of Simulated Water Level Controller, International Journal of Advanced Research in Computer Science and Software Engineering, Vol. 3, issue 11, pp. 328-332, 2013.

14. Shankari, M., Jyothi, M.E., Naveen, I. and Herle, H. Wireless automatic water level control using radio frequency communication, International Journal of Advanced Research in Electrical, Electronics and Instrumentation Engineering, Vol. 2, issue 4, pp.1320-1324, 2013.

15. Patil, Y. and Singh, R. Smart water tank management system for residential colonies using Atmega128A microcontroller. International Journal of Scientific \& Engineering Research, Vol. 5, issue 6, pp. 355-357, 2014.

16. Paul, S., Das, M., Sau, A. and Patra, S. Android Based Smart Water Pump Controller With Water Level Detection Technique. International Journal of Advanced Research in Computer and Communication Engineering, Vol. 4, issue 12, pp. 534-537, 2015.

17. K. Sandeep Varma, I. Hemalatha, K. Kishore Raju, A Smart Water Management System for Rural Area Water Tanks. Journal of Chemical and Pharmaceutical Sciences, pp. 29-33, 2016.

18. Santra, M., Biswas, S., Bandhapadhyay, S. and Palit, K., Smart Wireless water level Monitoring \& Pump controlling System, International Journal of Advances in Scientific Research and Engineering, 3, 2017.

19. PRASANNA LAKSHMI, VASAVI MOUNIKA, VEDA SRI, PRAGNA, MR. K. VIKAS Smart Water Tank: an IoT based Android Application, Iconic Research and Engineering Journals. Vol. 1, issue 9, pp. 162-165, 2018.

20. Shah, P.P., Patil, A.A. and Ingleshwar, S.S., 2017, February. IoT based smart water tank with Android application, in IEEE International Conference on I-SMAC (IoT in Social, Mobile, Analytics and Cloud) (I-SMAC), pp. 600-603, 2017.

21. Ravi, How to Remotely Control Arduino using Blynk App, ElectronicsHub, viewed 12 July 2019, https://www.electronicshub.org/control-arduino-using-b lynk/, 2019.

22. Emily Watkins, What is the Ideal pH of Drinking Water, Jason's Water Systems, viewed 20 May 2019, < https://www.jasonswatersofteners.com/what-is-the-ideal -ph-for-drinking-water/>, 2018. 